Bol. Acad. peru. leng. 67. 2020 (75-101)

\title{
NO TODOS LOS SUBALTERNOS SON IGUALES: EL MIEDO EN HERENCIA, DE CLORINDA MATTO
}

\author{
NOT ALL SUBORDINATES ARE THE SAME: FEAR \\ IN HERENCIA (INHERITANCE) BY CLORINDA MATTO
}

\author{
Mercedes Mayna-Medrano \\ University of Pennsylvania \\ mervic@sas.upenn.edu \\ https://orcid.org/0000-0001-7773-8255
}

\section{Resumen:}

En este artículo examinamos la novela Herencia (1885), de Clorinda Matto. Nos concentramos especialmente en el personaje afroperuano del libro, Espíritu Cadenas, y cómo este es configurado como un objeto de miedo. A partir de la teoría de género y de las emociones, estudiamos cómo Espíritu, como personaje subalterno, no tiene ninguna posibilidad de ocupar un lugar en la nación de postguerra imaginada por Matto, a diferencia, por ejemplo, del personaje mestizo de Margarita. De esta manera, a través del análisis de la estética naturalista usada por la autora peruana, nos damos cuenta de que, desde su perspectiva, existen sujetos subalternos que pueden ser salvados e incorporados en la nación republicana. Las conclusiones a las que llegamos muestran que la novela, bajo la influencia del naturalismo y su determinación sobre la herencia, representa al personaje afroperuano como un objeto que causa miedo y que, por lo tanto, no puede ser salvado,

https://doi.org/10.46744/bapl.202001.003 
https://doi.org/10.46744/bapl.202001.003

pues se siguen alimentando estereotipos que vinculan lo afroperuano con lo erótico, lo sexual y lo contaminado en el siglo XIX.

Palabras clave: naturalismo, miedo, afroperuano, nación.

\section{Abstract:}

In this paper we examine the novel Herencia (1885) by Clorinda Matto. We focus especially on the book's Afro-Peruvian character, Espiritu Cadenas, and how he is configured as an object of fear. Based on the theory of gender and emotions, we study how Espiritu, as a subordinate character, has no possibility of occupying a place in the post-war nation imagined by Matto, as opposed to the mestizo character Margarita, for example. In this sense, through the analysis of the naturalistic aesthetic used by the Peruvian author, we realize that, from her perspective, there are subaltern subjects that can be saved and incorporated into the republican nation. The conclusions to which we arrive show that the novel, under the influence of naturalism and its determination over inheritance, represents the Afro-Peruvian character as an object that causes fear and that, therefore, cannot be saved, because stereotypes that link the Afro-Peruvian with the erotic, the sexual and the contaminated continue to be fed in the 19th century.

Key words: naturalism, fear, Afro-Peruvian, nation.

Fecha de recepción:

$11 / 02 / 2020$

Fecha de aceptación:

$30 / 04 / 2020$

\section{Introduccción}

En la novela Herencia (1885), de Clorinda Matto, se narra la historia de dos familias: los Marín y los Aguilera. Los primeros son los mismos protago- 
https://doi.org/10.46744/bapl.202001.003

nistas de la canónica novela de Matto, Aves sin nido. Esta vez se encuentran en Lima y Margarita, su hija adoptiva, termina enamorándose de Ernesto Casa-Alta, con quien decide casarse y formar así una familia, que es la alegoría de la nación peruana. Por su parte, los Aguilera representan la clase alta limeña que debe extinguirse por su degeneración y falsos valores. La hija de este matrimonio, Camila Aguilera, termina casándose con el migrante italiano Aquilino Merlo, el cual había sido ayudado por la exlavandera de la casa, Espíritu Cadenas, quien hace el papel de celestina. Al final de la novela, Camila es víctima de violencia familiar por parte de su marido.

Mi propósito en este trabajo es mostrar, a partir de la teoría de las emociones y de género, que Espíritu está configurada a través del discurso del miedo, ya que, a través de la voz narradora, es señalada como un objeto que debe ser expulsado de la nación moderna por su triple condición de subalterna: mujer, pobre y negra. Su condición femenina es peligrosa, porque circula libremente por el espacio privado de la familia aristocrática criolla Aguilera, pues ha sido su lavandera; será esta condición, también, la que le permite tener una relación estrecha con Camila Aguilera, a quien influencia fácilmente por la débil herencia moral que esta ha recibido de su madre, Nieves Aguilera. Su condición racial es motivo de miedo, debido a que lo afro está asociado a lo sexual y corporal. Por tanto, Espíritu contamina a todo aquel que se relaciona con ella. Finalmente, es peligrosa por su condición de pobre, ya que la motivación económica será la que la impulse a «ayudar» al inmigrante italiano y dueño de una pulpería, Aquilino Merlo, en su afán de seducir a Camila, casarse con ella y así subir de estatus social. Entonces, estas condiciones serán las que constituyan a Espíritu Cadenas como un objeto de miedo que, por lo tanto, debe ser apartado de la nación imaginada por Matto.

\section{La herencia femenina: el miedo y los males sociales en la postgue- rra del Pacífico}

El contexto social del Perú en el que se produce la novela es el de la postguerra del Pacífico, en donde ciertos sujetos sociales provocan miedo en el imaginario del intelectual masculino y criollo. Este último se había visto vencido y feminizado durante la Guerra del Pacífico (1879-1883). A la par, durante este acontecimiento bélico, el negro y el indio se armaron 
contra el enemigo chileno, salieron de su condición subordinada y casi invisible en los campos y casas de blancos, y lucharon «codo a codo» con los hijos de las familias criollas. Este momento, además, dejó constancia del surgimiento de una nueva figura intelectual: la mujer ilustrada. Antes de la guerra, ya había empezado a escribir tímidamente novelas, poemas, ensayos; a participar y organizar veladas culturales, y a dirigir revistas. Después de la guerra, hizo más visible su ingreso a la esfera pública. Es entonces cuando Clorinda Matto hizo aparición como directora de El Perú Ilustrado, uno de los diarios más importantes del Perú, así como su mejor producción novelística, la cual solo era comparada con la de Mercedes Cabello, otra mujer que escribió libros de «escándalo» para la época, como Blanca Sol, cuya temática era la prostitución.

Sin embargo, la situación de las escritoras peruanas finiseculares se complicó luego de incursionar en el género de la novela naturalista-realista. Este era considerado masculino por su lenguaje descarnado y su narrador flaneur, quien, en sus paseos por el espacio público, contaba las escenas de la vida cotidiana, especialmente del bajo mundo. Ya en 1889, Mercedes Cabello había sufrido una serie de críticas por su novela Blanca Sol, en donde una mujer de clase alta se vuelve prostituta. Sin embargo, como afirma Ana Peluffo, después de la publicación de Herencia, Cabello tuvo una opinión muy crítica por considerar que Matto dejó de ser mujer al escribir novelas naturalistas: «Las opiniones hostiles de Mercedes Cabello sobre Herencia no dejan de ser irónicas porque la comunidad intelectual la había acusado unos años antes a ella misma de los delitos en los que supuestamente incurría su colega» (2005: 229).

No obstante, según Flor Mallqui (2013), a pesar de las convenciones de la época, las novelas de Clorinda Matto sí se construyen desde un realismonaturalismo, ya que buscan «mostrar los antagonismos latentes que impedían que el Perú se insertara en la modernidad» (p. 97). Esta situación tiene matices, ya que Matto sabe que hay ciertos mandatos que no puede sobrepasar y, por ende, dosifica su lenguaje. Para ello, incorpora elementos sentimentales que contrapesan los naturalistas, considerados masculinos. Como señala Peluffo (2005: 205), «en Clorinda Matto este "plot of decline" o "narrativa de la degeneración” convive con un culto a la domesticidad de filiación sentimental que 
https://doi.org/10.46744/bapl.202001.003

plantea la posibilidad de revertir los procesos de degeneración genética por medio de la influencia moral de la madre republicana».

El influjo de la madre republicana decimonónica, aquella que sirve a la nación desde el espacio sagrado del hogar (Peluffo, 2005: 77), sin embargo, tiene límites. Esto puede observarse en la relación madre-hija adoptiva entre Lucía Marín y Margarita, personajes centrales de Herencia. Es gracias a la influencia de la primera sobre la segunda que esta se convierte en una alegoría futura del ángel del hogar y, por tanto, fundadora de la familia burguesa, base de la nación peruana. En esta situación, la herencia racial andina de Margarita, quien es hija de una mujer indígena y un hombre blanco, es percibida como positiva por don Fernando Marín, esposo de Lucía. En oposición, no ocurre lo mismo con la comunidad afrodescendiente, representada por Espíritu. Ella es caracterizada a través de lo corporal y sexual, desde su físico hasta su oficio como prostituta. En otras palabras, a través de este énfasis de su cuerpo, está siendo representada como un ser contaminado. Al final, entonces, uno de los propósitos de la novela es expulsar el elemento afroperuano de la nación imaginada, pues son cuerpos contaminantes.

Ya desde el título, Herencia, el lector nota que la novela está marcada por el discurso cientificista de la época, donde la raza determina naturalmente el destino de cada persona: «El corazón de Margarita es tan puro como su sangre [cursivas añadidas]; será una buena esposa, madre y ama de sus hijos» (1974: 207). No obstante, como bien afirma Peluffo, la tensión entre este cientificismo y el sentimentalismo, "propio» de la retórica femenina de la época, hace que esta herencia adquiera en la novela también un aspecto educativo y moral: «Más adelante, sin embargo, se opta por una interpretación cultural del término en la que se afirma que los vicios y las virtudes femeninos se transmiten de madres a hijas a través de la educación moral» (2005: 227). Entonces, creo que es preciso reconocer que ambas herencias, la moral y la racial, juegan un rol importante en esta novela. Según esta lógica, no todas las razas expuestas a cierto ambiente y educación serán afectadas de la misma manera. Por ello, en el caso de la afroperuana Espíritu Cadenas, esta no puede ser salvada de la degeneración inherente a su raza y, a su vez, sus hijas podrían tener el mismo final si la Beneficencia Pública no se hace cargo de ellas. Sin embargo, Margarita, pese a ser mitad 
indígena, sí puede ser salvada, ya que tiene una sangre robusta y, además, una educación moral intachable, aprendida de Lucía Marín.

En el caso específico de esta novela, el lector nota que es la herencia femenina la que determina la vida y comportamiento de cada individuo. De esta manera, se establece una serie de relaciones hereditarias femeninas positivas y negativas. Por un lado, se encuentra la herencia moral que Nieves Aguilera extiende a su hija Camila, y que se ve reflejada en opiniones como las de José Aguilera, padre de la joven: «- iPerra!... iperra!... sí señor...la madre...y se me entregó a mí...la hija; es natural que se entregue a otro... ila ley hereditaria!... [cursivas añadidas] iperra! iperra!» (1974: 181). Se entiende de la cita que, así como la señora Nieves Aguilera tuvo relaciones sexuales prematrimoniales, también la hija puede hacerlo. Esto es «la ley hereditaria»: si la madre lo hizo, la hija lo hará. Evidentemente, la herencia de doña Nieves a su hija está relacionada a lo moral, al mal ejemplo y a las costumbres negativas. Por otro lado, distinto es el caso de Margarita Marín, quien recibió una herencia positiva:

La muchacha lleva sangre robusta, pura, está formada en la inocente vida de serranías, cuyo aire enriquece el oxígeno, desterrando ese azulamiento de la esclerótica que a los hombres de mi edad nos hace pensar en los hijos endebles, escrofulosos por el vientre materno, sí, por el vientre, raquíticos, de imaginación viva e inflamable como el vino de champagne, terrible herencia que yo deseo evitar a los hijos de Margarita. La muchacha tampoco les llevará a las bijas de usted la herencia que llevan en su sangre las hijas de las mujeres aperradas [cursivas añadidas]. (1974: 207)

Aquí se destaca la herencia genético-racial-ambiental, es decir, científica para la época, de Margarita, quien posee una herencia robusta e inocente de las serranías. Este es un aspecto importante a considerar, ya que implica que para Matto la base para la reconstrucción de la nación peruana tras la Guerra del Pacífico está vinculada con valorar positivamente la herencia indígena, encarnada en Margarita, quien es una mestiza (de madre india y padre blanco). Obviamente, a esto se suma la educación recibida por parte de Lucía Marín. Ella cumple un papel fundamental en la herencia moral y educativa que le brinda a la joven, y que, como 
https://doi.org/10.46744/bapl.202001.003

madre republicana, logra convertirla en el futuro ángel del hogar. Debido a ello, Margarita no heredará lo que las mujeres «aperradas», como doña Nieves, le heredan a sus hijas: los vicios que impiden la formación de una sociedad moderna. Su herencia, en cambio, es positiva. Después de lo visto, se puede afirmar que la novela se estructura sobre la base de la herencia femenina, tanto racial como educativa.

Vamos descubriendo, entonces, cómo en Herencia se problematiza la situación del sujeto femenino, el cual tiene la posibilidad de convertirse en un objeto de miedo. Para evitar esto, necesita ser encausado por las sendas de la contención sexual y la educación occidental. De este modo, uno de los cuerpos más temidos dentro de la novela es justamente el de la afroperuana Espíritu Cadenas. Ella, además de encarnar los males sexuales (prostitución, lujuria, etc.) que se creía que las mujeres negras heredan a sus hijas, simboliza, por su raza y su condición socioeconómica, una serie de vicios que contaminan y colaboran con la pérdida del honor de las familias peruanas.

En el caso específico de la comunidad de afroperuanas, Patricia Oliart menciona que los autores decimonónicos concebían que existía una gran cantidad de ellas en la Lima del siglo xIx. Su conclusión es que «su visibilidad era notoria para los habitantes de Lima. Y, en efecto, en la literatura de la época, las negras y mulatas son mencionadas numerosas veces y desempeñando diversos roles» (1995: 282). Esto, a su vez, nos ayuda a entender que las mujeres negras y mulatas transitaban con mucha libertad en el espacio público, lo cual sucede porque desempeñaban diversos roles laborales, como tamaleras, fruteras, verduleras, entre otros. Esta situación es importante debido a que, en el siglo XIX, se consideraba que el espacio «natural» de las mujeres era el privado y, en contraposición a él, el espacio público era de los hombres y de los avatares políticos.

Otro aspecto a considerar es también la presencia de la mujer negra en el espacio privado, especialmente como nodriza o ama de leche. Recordemos que, como sostiene María Emma Mannarelli, la maternidad se constituye como parte de la identidad femenina recién a fines del siglo XIx (1999: 358). Antes, era normal que alguna mujer negra o mulata amamante y críe a los hijos de las familias criollas, lo cual, además, era un 
trabajo heredado desde la época de la esclavitud. Como sostiene Marcel Velázquez, siguiendo a Fox-Genovese: «la mujer [negra] trabajaba en el cuidado de los niños, la cocina, y se incorporaba a la familia de los amos como una sirvienta» (2001: 73). Es decir, ellas tenían un tránsito libre en el espacio familiar.

Esta situación es problemática, pues, ya desde textos del siglo XviII en los que se evidencia un discurso «civilizador», se observa un temor a esta intimidad de las mujeres afroperuanas en las familias criollas, ya que se las concebía como elementos dañinos y contaminantes:

Existe un texto del Mercurio Peruana dedicado íntegramente a la nefasta influencia de las amas de leche (negras esclavas) sobre los niños y la totalidad de la familia. Se destaca la autoridad que adquiría la esclava sobre la niña que amamantó, sobre los otros criados e incluso sobre la madre que aceptaba pasivamente esa situación. El conflicto se plantea entre: una voluntad masculina que desea dividir y separar un tramado de poder en el ámbito privado, marcadamente femenino (la nodriza esclava-la niña-la madre) y la recuperación del control real de sus hijos. (Velázquez 2003: 64)

Vemos cómo ya muy inicialmente el problema del sorismo, la hermandad entre mujeres, causaba gran malestar a los sujetos masculinos. Esta situación se vuelve un mal que había que evitar, ya que la influencia de la mujer negra sobre las mujeres blancas, niñas, jóvenes y adultas, socavaba el poder del ciudadano masculino criollo. Este problema seguirá en el imaginario colectivo y lo vemos también en la novela Herencia, con algunos matices que analizamos más adelante.

Otro aspecto importante a señalar es la asociación entre sexualidad y cuerpo del sujeto afro, el cual causa miedo por su potencia. Como menciona Velázquez, "[e]sta tendencia formalizaba los temores de la clase dominante: el miedo a la rebelión, y la angustia ante la potencia sexual de los negros (temor de que violasen a las mujeres blancas y la envidia ante la inagotable capacidad de goce sexual de las esclavas [cursivas añadidas]» (2003: 66). Sobre este aspecto, un estudio realizado por 
https://doi.org/10.46744/bapl.202001.003

Francesca Denegri acerca de la presencia del sujeto negro en la obra Eleodora, de Mercedes Cabello, y El ángel caído, de Juana Manuela Gorriti, ejemplifica bien esta situación. En él, Denegri sostiene que este personaje, socialmente marginal pero simbólicamente central, «destaca por su sexualidad cruda y desenfrenada» (2003: 131). En el caso específico de las mujeres negras, algunos autores de la época aseguraban que «eran ellas quienes iniciaban sexualmente a los hombres» (Oliart, 1995: 282). De esta manera, este cuerpo subalterno está vinculado a lo erótico en la literatura peruana y en el imaginario colectivo de la época.

Esta situación no parece cambiar a finales del siglo XIX, sino que más bien parece reforzarse desde este cientificismo racista que existe en aquel momento. Como señala Oliart: «[S]e puede mostrar cómo el racismo de la sociedad oligárquica peruana, aunque tuviera antecedente inmediato en la Colonia, es activamente reformulado en el siglo xIx, con un discurso renovado y con propósitos bastante específicos» (1995: 262). Entonces, nos encontramos frente a la existencia, dentro del imaginario del peruano del siglo xix, de un miedo a este cuerpo sexual. Esto se refuerza con la liberación de los esclavos, pues, «se percibe un temor posterior a la abolición de la esclavitud respecto a las dificultades que podría traer el disciplinar esa mano de obra liberada, ya que se decía que a los afroperuanos no les gustaba trabajar» (Oliart, 1995: 276).

En relación con la situación racial peruana, luego de la Guerra del Pacífico, el concepto de mezcla racial se vuelve un pasivo negativo para la nación. Como menciona Klaiber, «la victoria de Chile sirvió para confirmar, fortalecer y aún popularizar el mito de la superioridad racial chilena. Por otra parte, la guerra también tuvo como consecuencia la reacción justamente inversa en el Perú» (1978: 27). De hecho, como indica el autor, los indios fueron el principal blanco de ataque de la prensa de Chile. Junto con ellos, la mezcla de razas degeneraba al Perú según los chilenos:

Además de estas alegaciones acerca de las instituciones democráticas y capacidad para trabajar, la prensa chilena frecuentemente señaló la homogeneidad racial como uno de los factores importantes para explicar las victorias chilenas en la guerra. [...] Declaró el comentador, airadamente, 
que a diferencia de esa naciones (el Perú y Bolivia), con sus 'indios aborígenes, negros o mestizos de varias castas', Chile se distinguió precisamente por su unidad de raza [cursivas añadidas] y por su asimilación de las mejores razas de Europa. (1978: 29)

Si bien el estudio de Klaiber se orienta a la problemática situación del indígena después de la guerra con Chile, es claro que también los negros fueron vistos como una raza que restaba oportunidades para la construcción de un Perú moderno. De hecho, como explica Basadre, la pérdida de la guerra no solo dejó una gran crisis económica en todo el país, sino un «complejo de inferioridad, el empequeñecimiento espiritual, perdurable jugo venenoso destilado por la guerra, la derrota y la ocupación» (2005: 11). Este fue el sentir de los intelectuales decimonónicos, como González Prada y Matto, que se comprometieron con la reconstrucción nacional desde las letras.

De esta manera, llegamos a un aspecto central de este trabajo y que se puede resumir en dos preguntas: ¿qué características convierten a un sujeto en un objeto del miedo? y ¿cómo se puede lidiar con este? Martha Nussbaum define el miedo como un sentimiento útil, que aparta a quien lo siente del peligro (2014: 386). Sin embargo, pese a este beneficio, el miedo tiene el problema de ser un sentimiento muy estrecho, ya que lo que termina importando es «el propio cuerpo del individuo que lo experimenta y, quizás, por extensión, su vida y las personas y las cosas directamente conectadas con ellas» (Nussbaum, 2014: 388). Es decir, es un sentimiento que termina cerrando a los sujetos hacia las fronteras más cercanas de sí mismos y los suyos, y que deja fuera a todo un número importante de otros. Sobre lo que ocasionaría, Nussbaum señala:

las personas pueden aprender a temer por un simple efecto asociativo a colectivos de personas a los que la cultura relaciona con lo invisible o lo oculto, o con lo artero o lo sinuoso: toda la sarta de estereotipos usados a lo largo de los siglos para demonizar a los grupos minoritarios. (2014: 388)

De esta manera, nos encontramos con un sentimiento que aleja a los unos de los otros, ya que convierte a algunos en un objeto de miedo, 
https://doi.org/10.46744/bapl.202001.003

el cual debemos mantener lejos de nosotros para cuidarnos de cualquier posible peligro.

Al igual que Nussbaum, Sara Ahmed explica cómo funciona el mecanismo del miedo a través de una economía afectiva; es decir, «it does not reside positively in a particular object or sign» (2004: 64). Por ende, el miedo circula entre nosotros y, por ello, necesitamos fijarlo para identificarlo y apartarlo: "If fear had an object, then fear could be contained by an object» (Ahmed, 2004: 65). Esto significa que identificar un cuerpo como nuestro objeto de miedo permite que este sea apartado y, por tanto, no amenace nuestro yo ni nuestra existencia, pero ¿cómo se vuelve un cuerpo un objeto de miedo? Ahmed, siguiendo las ideas de Homi Bhabha, explica que «[s]tereotypes seek to fix the meaning of the other, but the very repetition that is required to enable such a fixation renders them a site to insecurity to security» (2004: 64). Por ello, la repetición de estereotipos acerca de algún cuerpo permite que este se fije con ciertos significados que convierten ese cuerpo en un objeto de miedo, el cual debemos apartar de nosotros para evitar que nos haga daño y así estar seguros.

En ese sentido, Ahmed afirma que el miedo sirve para asegurar la relación entre los cuerpos. Los reúne y los aparta a través de los temblores que se sienten en la piel, en la superficie que aflora a través del encuentro (2004: 63). Entonces, el miedo es un sentimiento que sirve para organizar el espacio y las formas en que los cuerpos se mueven dentro de él: «fear works to contain some bodies such that they take up less space» (Ahmed, 2004: 69). Asimismo, cualquier apertura hacia el otro se ve como peligrosa, ya que el otro, gracias a la repetición de estereotipos antes mencionada, es interpretado a través de esta narrativa del miedo: «the response of fear is itself dependent on particular narrative of what and who is fearsome that are already in place» (Ahmed, 2004: 69). De este modo, el miedo es un sentimiento que nace como respuesta frente a lo que creemos es una amenaza. Esta situación se resuelve convirtiendo a un sujeto en nuestro objeto de miedo. Solo de esta manera podemos contenerlo y, así, apartarlo de nosotros. De esta manera, alejamos el peligro que supuestamente trae para nuestra existencia y la de los nuestros. 
https://doi.org/10.46744/bapl.202001.003

\section{Espíritu, seres que asustan}

En un análisis muy interesante de este personaje, Ana Peluffo sostiene que el nombre de Espíritu es irónico en la medida en que «su identidad deriva de la conversión de su cuerpo en mercancía» (2005: 225). Es decir, desde la lectura de Peluffo, hay un contraste entre el nombre que se le asigna, ligado a lo ideal, y lo que se ve en la novela, donde está más relacionado a lo corporal. A esta lectura que hace Peluffo me gustaría agregar aquella en la que el significante espíritu no esté ligado a lo espiritual-idealista, sino más bien a este espíritu sombrío que se cierne sobre los cuerpos vivos y luminosos. Entonces, Espíritu Cadenas es, desde su nombre, un personaje creado para ser temido, pues ensombrece la vida familiar de los Aguilera y termina por precipitar la destrucción del honor de la misma.

Es importante considerar, como sostiene Peluffo, que «[e]l sujeto narrativo oscila entre considerar a la mujer pública [como lo es Espíritu] como un personaje degradado por raza y clase (visión que toma del naturalismo canónico), o como una víctima de la sociedad y de la lujuria masculina» (2005: 222). Esto se observa cuando el sujeto narrativo se refiere a estos personajes como «criaturas desgraciadas» y señala la culpabilidad de la sociedad en esta situación. Sin embargo, creo que en esta oscilación para el caso específico del sujeto femenino negro, como lo es Espíritu, las restricciones en sus posibilidades de regeneración son más evidentes. En otras palabras, ella termina muerta y su deceso es publicado en el periódico La Opinión Nacional como aviso del peligro que encarna y un castigo a sus excesos. Por tanto, la forma en la que este personaje es configurado en la novela revela cómo este será imposible de ser salvado.

Un primer aspecto que se destaca es su físico: «morena alta, fornida, de caderas anchas y brazo hombruno, pero no sólo enflaquecida, sino chorreada, consumida por la escasez a que llegó después de la muerte de la señora Ortiguera, su madrina y protectora» (1974: 52). En este sentido, Peluffo señala que "[l]a Espíritu de Herencia no es una prostituta con pretensiones de clase, sino una 'ex-sirvienta mimada de casa grande', en la que el acceso a la prostitución ocurre más por necesidad económica que por predisposición genética» (2005: 223). En relación a esta afirmación, 
https://doi.org/10.46744/bapl.202001.003

me parece necesario analizarla con mayor cuidado. Es decir, es cierto que el declive de Espíritu inicia cuando se encuentra fuera de la protección de una mujer blanca, que podríamos considerar una posible madre republicana, y que accede a la prostitución por necesidad. Sin embargo, su cuerpo, como se describe en la cita anterior de la novela, la predisponía a este comportamiento erótico y sexual. En otras palabras, su mismo cuerpoherencia genética la convierte en un sujeto sexualizado y potencialmente erótico. Este es un aspecto central para entender la configuración de este personaje afroperuano.

No parece pasar lo mismo con el sujeto mestizo Margarita, por ejemplo, quien, a causa de la educación que recibe por parte de los Marín, aprende a contener sus deseos «insanos» (los que sintió por Manuel, quien resultó ser su medio hermano) y termina posibilitando una relación fundacional con Ernesto Casa-Alta, representante de una familia aristocrática empobrecida:

Ernesto se contrajo por una conmoción nerviosa desconocida para la virgen y agarrándola fuertemente se llegó al altar sin soltar a su desposada de cuya blanca corona nupcial se desprendieron dos azahares en botón y cayeron al alfombrado de Bruselas, rozando en su caída la frente del marido de Margarita, quien repitió por tercera vez: - iPoseer es triunfar! [cursivas añadidas] (1974: 247)

Como se observa en la cita, al final de la novela se consuma el matrimonio entre Ernesto y Margarita, y se insinúa la posibilidad de la fecundación, que traerá el triunfo para la fundación de una nación moderna en la que se unan la buena aristocracia y la burguesía con herencia serrana.

En cambio, en relación a Espíritu, se destaca su corporalidad y, con ello, se impide que ingrese en la comunidad imaginada ideal que Matto intenta esbozar. Como sostiene Mallqui:

los personajes antihéroes en Herencia como Nieves y Camila Aguilera, Aquilino Merlo y Espíritu Cadenas son representados a través de un lenguaje corporal y sexual, el cual tiene como función principal demostrar que estos sujetos son los entes que impiden la formación de una nación moderna. (2013: 105) 
Entonces, en Herencia, se consolida la narrativa del miedo en relación al cuerpo negro, considerado sexual y erótico, lo cual es necesario para, como diría Ahmed, convertir a Espíritu en un objeto de miedo.

Además, Espíritu Cadenas, en correspondencia con estos atributos sexuales, posee un carácter despreocupado, en el que destacan sus inclinaciones hacia las fiestas: «Encendió la vela, examinó a sus dos hijas que con las cabecitas juntas, dormían como dos bolillas de azabache. Sacó los cinco billetes guardados y regresó a la parranda [cursivas añadidas], apagando la vela y asegurando la cerradura de la puerta» (1974: 110-111). De esta manera, Espíritu, pese a su pobreza, es capaz de gastar su dinero para solventar una fiesta. Esta acción evidencia las inclinaciones «viciosas» de este personaje al cual ni siquiera el amor de madre, que parece poseer, puede salvar.

En la cita anterior, Espíritu parece vacilar sobre lo que va a hacer al ver a sus hijas, pero su amor de madre, inherente a todo sujeto femenino desde la concepción de Matto, parece desaparecer bajo los vicios que forman su carácter. De hecho, el amor de madre la hace trabajar, pero, desde la voz narradora, se la juzga como parte de un grupo social ínfimo y lleno de vicios:

No obstante, en la lucha por la doble existencia, la suya y la de su hija, apeló a varias industrias, entre ellas la de corredora de muebles viejos, y fue siempre en descenso, hasta llegar a ser tamalera, oficio generalizado, pero socorrido, sólo para dar pábulo a la crápula [cursivas añadidas]. (1974: 53)

De esta manera, junto con otros personajes, Espíritu vive una vida llena de vicios, de la cual ni su «natural» inclinación al amor de madre puede salvarla, pues ganan en ella los vicios que, por su naturaleza también, posee. Así, sobre la necesidad:

la obligaba a frecuentar la chingana [...] y como consecuencia nacía la necesidad de hacer la mañana y festejar el San Lunes [cursivas añadidas], casi siempre en unión del celador de la esquina, de Cosme el mocho, carretero de oficio, del suertero don Policarpo leva larga, y de alguna cocinera en actual servicio. (1974: 53) 
https://doi.org/10.46744/bapl.202001.003

Podemos notar cómo, en la novela, Espíritu Cadenas se configura a través de una narrativa que la caracteriza como un ser contaminado. Esto sucede porque se desplaza con libertad por el espacio público al ser tamalera o visitar chinganas, lo cual, además, insinúa la situación de prostitución a la que ha llegado. Recordemos, como señala Peluffo, que «[d] e acuerdo a los postulados de la ideología doméstica liberal, la virtud del sujeto femenino era directamente proporcional a su mayor y menor grado de aislamiento con respecto al contaminado mundo de la carne y la política» (2005: 208). No obstante, también, su peligro reside en el fácil acceso que tiene al espacio privado y familiar de los Aguilera, lugar al que puede ingresar con libertad por haber sido previamente su lavandera. En ese sentido, es un cuerpo que circula con demasiada libertad; por ello, es necesario contenerlo y mantenerlo lejos de las familias criollas si no quieren contaminarse. El cuerpo de Espíritu Cadenas debe ir ocupando, en el vocabulario de Ahmed, cada vez menos espacio.

Además, la relación que establece con Camila es demasiado horizontal, lo que refleja la mala educación que esta ha recibido de su madre: «-Hola, Espíritu ¿de dónde pareces?- dijo Camila que llegó. - Aquí tiene usté ñiita a su morena que viene a saludármela. iTan linda!- dijo ella llegándose en ademán de abrazarla e inclinando la columna dorsal con estudio manifiesto» (1974: 150). De hecho, se puede ver cómo Camila no tiene ningún reparo en expresar algún tipo de ademán cariñoso. De esta manera, el acceso libre por el espacio privado que tiene este cuerpo contaminado por los vicios del espacio público, sumado a su condición «natural» ligada a lo corporal, lo convierten en un objeto de miedo. Este debe ser identificado, contenido y apartado si es que se quiere evitar la ruina de las familias peruanas y, con eso, la imposibilidad de formar la nación moderna. Por ende, Herencia se convirtió en una advertencia: hay ciertos cuerpos que deben ser temidos y, en ese sentido, es necesario que se aparten. Las consecuencias de esta libre circulación se analizan con mayor detenimiento más adelante.

El motivo por el cual Espíritu Cadenas se convierte en objeto de miedo es porque cumple con una función celestinesca clave en la relación entre Aquilino Merlo y Camila Aguilera. En un artículo anterior (2012), 
analicé la figura de la beata en El Padre Horán (1848), de Narciso Aréstegui. Propuse que este libro se concebía como una novela didáctica. En ella, se presentaban formas de ser femeninas y una de las que más se criticaba era la de la beata por concebírsela como un rezago colonial (religioso) que impedía la formación de la nación moderna. El mal que esta beata hacía estaba ligado a su comportamiento como celestina, en el caso de esa novela, entre el cura Horán y la niña Angélica. Considero que la misma función cumple Espíritu. Ahora, sin embargo, su cuerpo encarna un nuevo objeto de miedo: el de una raza considerada inferior, viciosa y contaminada.

De esta manera, en el encuentro entre Espíritu y Aquilino, nace en el pensamiento de este la posibilidad de seducir a Camila:

¡Hola! iY qué preciosa que está la ña Camilita! Dios me la guarde.

Sí, que la guarde Dios. Está hermosa como las vírgenes de mi país, de comérsela»...

Y cuidau, pues, ño Aquilino, que aquí muchos ban venío con su cara y sus ojos de usté se han subio al trono- dijo riendo Espíritu, levantando al mismo tiempo la caja de fósforos y la velilla de sebo envuelta en papel amarillo, y fijando su mirada_intencionada en el rostro del vendedor.

Aquilino sonrió también, pero con una sonrisa extraña, chispeáronle los ojos, y el corazón dio un vuelco en el pecho. [...]

Pudiera sí... pudiera no... doña Espíritu... si usté me ayuda.

$[\ldots]$

Las palabras de Espíritu revoloteaban en su cerebro como moscas de Milán, picándole aqui y allá, hasta producirle la desazón calenturienta que determina los grandes crímenes, los heroísmos, o las simples infamias ejecutadas en el momento patológico. (1974: 47-48)

En la cita anterior, se puede notar que es Espíritu quien empieza a hablar sobre la belleza corporal de Camila, con lo que desata en Aquilino los bajos deseos que este posee, evidenciado en palabras como comérsela, una explícita referencia sexual. Espíritu, por su parte, reconoce las malas intenciones del italiano y las alienta al mencionarle que otros, con sus características, ya lo han logrado. Por tanto, son justamente las palabras de Espíritu las que impulsan los bajos deseos de seducción de Aquilino: 
https://doi.org/10.46744/bapl.202001.003

[...] y el deseo de poseer una por voluntad, deseo que dormía en el fondo del alma, despertó sacudido por la voz de Espíritu: mejor dicho, así como la chispa que brinca del pedernal basta para encender la yesca, la pasión carnal y la codicia del dinero brotaron al roce de aquellas palabras animadoras. 'Otros que han venido con la cara de usted, se han subido al trono' [cursivas añadidas]- se repetía Aquilino; y su fantasía se convertía en espejo de cuerpo entero, [...]. (1974: 49-50)

Por ende, Espíritu cumple un papel central en despertar en Aquilino la idea poco honorable de seducir a Camila y satisfacer sus deseos carnales y monetarios.

El segundo aspecto por el cual Espíritu cumple un rol celestinesco en la novela y, por ello, se convierte en objeto de miedo es su alianza estratégica con Aquilino Merlo. Es decir, no es posible que Espíritu sola precipite la desgracia de los Aguilera, sino que esto sucede por su unión con Aquilino. Él tiene la agencia necesaria para convertirse en el sujeto que desgracie a Camila y le impida ser un futuro ángel del hogar. Esta alianza los convierte en seres peligrosos. En relación con esto, Peluffo señala lo siguiente:

Uno de los ejes narrativos de Herencia es una 'ficción paranoica' que busca generar en el lector miedo y fobia por un inmigrante deshumanizado al que se asocia con la degeneración nacional. La otredad del inmigrante que no habla bien la lengua y que tiene hábitos y costumbres foráneos es difícil de asimilar a un proyecto nacional que somete las diferencias a un intenso proceso aculturador. En la antonimia semántica que se establece entre formas virtuosas y anti-virtuosas de masculinidad republicana, se coloca al inmigrante italiano en el segundo polo, por su falta de racionalidad y control a la hora de dominar sus pasiones. (2005: 235)

Entonces, en la novela, nos encontramos frente a un sujeto masculino que, como el sujeto negro del que hablábamos en la primera parte de este trabajo, es temido por su fuerza sexual y erótica:

Y sin meditar más que un segundo, se lanzó sobre la hija de doña Nieves, la más orgullosa dama de falsos pergaminos que rodaba carruaje en las calles de Lima; y ciñó su cintura con férreo brazo, la levantó en alto sobre sí, y al 
mismo tiempo que sus labios de fuego profanaron los labios de carmín de la niña, la actitud de su cuerpo profanó el alma de la virgen [cursivas añadidas]. (1974: 81)

Se observa en la cita anterior cómo Aquilino Merlo procede sin pensar, es decir, como un ser animalizado que actúa pasional y no racionalmente. Su actitud sexual es tan potente que se «lanza» sobre su víctima, como si esta fuera una presa. Asimismo, sus labios son de "fuego", lo cual describe bien las emociones sexuales que vive en ese momento; lo más importante es que esa actitud termina por «profanar», cual sujeto sacrílego, a la virginal Camila.

De la misma manera, una forma en que Aquilino confunde a su víctima es a través de su físico, pues es guapo, ya que tiene «grandes ojos azules, su color róseo, sus patillas y bigotes finos, sedosos, rubios, sirviendo de marco a la dentadura de porcelana» (1974: 50). Por lo tanto, puede engañar a las mujeres que solo se fijan en el aspecto físico de los hombres, como Camila, sin preocuparse por las conveniencias morales y sociales de sus elecciones.

La alianza de Espíritu y Aquilino se hace realidad y, así, la intervención de Espíritu no queda en una simple idea, sino que ella se convierte en el instrumento efectivo a través del cual el italiano puede llevar a cabo sus planes:

iEstá uste... de cenársela! ... iEsos ojos!... buena que la habrá dado usté mi guapa- dijo Aquilino halagando a la morena con el tacto del hombre que ha viajado mucho y ha visto mucho, y que reconocía en aquella mujer el instrumento preciso para llegar al desenlace de la historia de Camila, [cursivas añadidas] iniciada con todas las probabilidades de éxito. (1974: 134)

De esta manera, Aquilino está seguro de que la afroperuana será el objeto a través del cual concretará sus planes deshonrosos, ya que sabe que Espíritu puede conseguir que él entre a la casa y, también, porque reconoce que puede comprarla con dinero. Es decir, ella no tiene la virtud suficiente para poder rechazar el dinero que él le ofrezca: 
https://doi.org/10.46744/bapl.202001.003

- Usté tiene la culpa, ña Espíritu, usté las compondrá todas. - Desde luego, y como $p a$ mi ha de ser la mitra de páo me toca el buen servicio y la iligencia. - Gracias, yo no seré ingrato [cursivas añadidas]. - iGuá! no será uste el santo primerito que yo ponga en trono de plata. (1974: 135)

En este caso, es claro que Espíritu no unirá gratuitamente a Aquilino con Camila, sino que está esperando una retribución monetaria por ello. Además, destaca de lo anterior que este no es un caso aislado, pues la afroperuana Cadenas conoce el oficio de celestina.

Por tanto, se podría afirmar que es el lazo entre la clase baja, migrantes y negros, lo que precipita la destrucción de las familias peruanas criollas. Así, tenemos a Espíritu quien, a través de la agencia de Aquilino Merlo, termina causando la deshonra de Camila, obviamente ayudada por la mala educación que esta recibe de su madre, Nieves Aguilera. De esta manera, Espíritu es un objeto de miedo. No obstante, en algún momento de la novela, este objeto, ya identificado por la voz narradora como contaminante, parece salirse de control, incluso para el propio Aquilino:

- Me entrego en sus manos, ña Espíritu, ña Espíritu- repetía Aquilino con ademanes que hicieron levantarse de su asiento a la mujer y decirle: - Güeno: armo yo la canasta, y en la canasta...va usté..put...la madre, put... la bija, put...la manta que las cobija- agregó riendo la mulata y cerrando malisiosamente los labios, después de lanzar tamaño refrán, hizo una cruz sobre ellos.

El italiano se puso rojo como un tomate, mas, reponiéndose, contestó:

Trato cerrado [cursivas añadidas]; pero ha de ser de noche, porque de día no puedo dejar la tienda. (1974: 137)

La cita anterior es muy interesante, pues, hasta ese momento, Aquilino parece pensar que tiene bajo control a Espíritu, quien es considerada como un instrumento que él usa para su beneficio. Sin embargo, en esta escena, Espíritu parece corporizar una nueva imagen, la cual Aquilino no se espera, ya que se manifiesta su calidad de agente al usar un vocabulario soez («put...») y con una actitud maliciosa clara («cerrando maliciosamente los labios»). Esto causa en Aquilino un sentimiento de 
vergüenza y de asombro («rojo como un tomate») ya que ve en Espíritu el reflejo patente de sus deshonrosos planes. En ese momento, no hay nada que esconder. La alianza ha sido sellada entre ambos personajes, socialmente marginales, pero simbólicamente centrales, en vocabulario de Denegri. Ambos se ayudarán y terminarán precipitando la deshonra de los Aguilera.

Es evidente también que Espíritu no necesita de Aquilino para idear el plan que la acercará a Camila: «Con que, trato de juez de paz: yo cumplo lo que ofrezco, y mañana será otro día, patroncito- dijo saliendo precipitadamente, sin dar lugar a que el italiano le diese instrucciones de ningún género y pensando en la propina que le produciría aquel servicio [cursivas añadidas]» (1974: 137). Espíritu actuará después para su conveniencia económica y construirá ella misma el plan que unirá a Camila y Aquilino, el que será la perdición de la primera.

Finalmente, como señalé anteriormente, la función celestinesca de Espíritu es facilitada por su entrada sencilla al espacio privado de los Aguilera. Como se indica en el libro, Espíritu fue lavandera de esta familia y, por ello, la conocen: «Pretexto de cocina o de lavado no hae fartar. Las mujeres son mujeres y los hombres son hombres- pensó ella y siguió su camino» (1974: 138). Se puede notar en la cita anterior que Espíritu es consciente de que puede ingresar al espacio privado de los Aguilera porque ha trabajado para ellos y ha tejido «redes de amistades» con las mujeres criollas. Por tanto, Espíritu decide buscar a Camila, quien la recibe:

iTan hermosa!- repetió la morena y llegándose más a Camila dijo a media voz:- Niita, ese Aquilino tan buen mozo, tan arreglau, tan simpático, está loqueau por_hablar a usté dos palabras. Diz que si usté no lo concede dos palabras se tira un tiro iJesús! está loqueau.

$[\ldots]$

Mire ñita que con esas cosas no hay que jugarse. Tantos hombres no se han pegau un tiro por cosa e náa. Yo seré la única que sepa. ¿Qué necidá hay de que nadie se imponga de que usté hable o no hable?

iChist!

Si ná de malo hay tampoco. (1974: 150) 
https://doi.org/10.46744/bapl.202001.003

En la cita anterior, nos encontramos con la perfecta ilustración de la viveza de Espíritu, quien decide decirle a Camila que, si no recibe a Aquilino, este se va a suicidar, lo cual, de alguna manera, produce un efecto de compasión sobre la joven. Asimismo, se presenta como su amiga comprensiva: "Yo seré la única que sepa», y también distorsiona la moral de la joven, pues asegura que «nada de malo hay». Entonces, Espíritu tienta a la joven para que acepte ver a Aquilino, pese a que conoce cuál será el resultado de ese encuentro.

Además, ante el consejo de Espíritu, Camila recuerda que nada de malo hay en recibir a hombres, pues su madre, doña Nieves, hace lo mismo al recibir «visitas extrañas». Por tanto, aquí también interviene la herencia negativa de doña Nieves sobre su hija. Con esto, el libro nos da a entender que, si Espíritu logra tener alguna influencia sobre Camila, se debe a que ya está predispuesta por la mala herencia educativa y moral que tiene. En ese sentido, en esta conversación, la «maldad» de Espíritu se ve claramente: «Espíritu permanecía cerca de Camila con esa frialdad estoica del cansancio pasional que ya sólo saca fuerzas para ayudar al mal de otros, mirado como un bien tras el engañoso prisma de las groseras exigencias materiales [cursivas añadidas]» (1974: 151). Para Espíritu, esta situación es solo un trámite más. No tiene conciencia de que puede arruinar la vida de Camila. Entonces, ante la duda de esta, comenta: «¿Su mamacita de usté no recibía a tanto pobre, con voluntá?- dijo Espíritu precisando la contestación; pero al notar que la niña estaba turbada plenamente, aprovechó del silencio de Camila para decirle: Lo voy a traer, ñita esta noche, de nueve para adelante. Sí, sí» (1974: 151). De esta manera, el poco juicio que le queda a Camila se ve opacado por la viveza de Espíritu. Esta última toma la decisión de pactar el encuentro entre Aquilino y Camila, aunque no haya recibido una respuesta afirmativa de la joven. Esto sucede por el alto grado de intimidad entre ellas y por la influencia que ejerce una sobre la otra.

Ya después de este acuerdo, Aquilino logra su cometido: seducir a Camila y tener relaciones sexuales con ella, lo cual le asegura su matrimonio y tener la fortuna de los Aguilera. No obstante, el destino de la joven termina siendo preocupante, pues está casada con un hombre abusivo: 
[...] la persona de Aquilino Merlo, quien presa de una alucinación mental retrocedió ante su misma imagen y después, reaccionando, se lanzó sobre el mullido lecho y arrancando de su sueño a la mártir [Camila] la derribó sobre el aterciopelado alfombrado de Bruselas exhibiendo un esfera de marfil bruñido en cuya redondez estampó dos palmadas [cursivas añadidas] cuyo sonido repercutió en el silencio de la madrugada. (1974: 242)

De esta forma, Camila es víctima de abuso doméstico por parte de su esposo alcoholizado, quien no repara en su condición de mujer embarazada («redondez»). La imposibilidad de que este matrimonio triunfe es evidente: Camila no es ni será un ángel del hogar. La lección pedagógica debió de ser clara para los lectores de libro: eduquen bien a sus hijas y no dejen la entrada libre a sus casas a seres de clases bajas, que se «ha comprobado», a través de una serie de narrativas de miedo, que están contaminados por vicios sexuales e insanos. Este cuerpo, ahora, tiene demasiada libertad para circular en el espacio privado y, al ser un objeto contaminado, podría causar daño si no es controlado. Si queremos evitar ese mal en el futuro y salvarnos, debemos hacer que ocupen el menor espacio posible dentro de la nación o, si es posible, expulsarlos de ella. Esto sería una cuestión de supervivencia de lo que somos o, para el caso peruano de Matto, para lo que quería que llegáramos a ser: modernos y civilizados.

Me gustaría destacar aquí, como ya indiqué antes, que la voz narradora siente una gran ambigüedad ante la situación de Espíritu. Por ejemplo, después de pactar el encuentro entre Aquilino y Camila, Espíritu piensa:

Felizmente la cosa no es con señora casáa que así podría entrar comején... yo, no, no, a las casáas ni por pensamiento... jJesú! con doncellas en estao maduro, eso sí, que es prestar servicio, y luego... ¿acaso lo hago yo por la plata de mi amo? no señó, por servir a ño Aquilino, que sea icho en verdá, es un mozo bien plantao iEsos ojazos! ... iJesú! si parece que estoy loquáa... pero ha dicho la ñia que a las nueve, y... a las nueve y media, mi caserito ya sabrá a qué atenerse y la ñiita Camila a qué atenerse. Yo le debo gratitú, bueno, y los apuros que me quita con su fiao cuando ésas chillan...- Las últimas palabras recordaron a 
https://doi.org/10.46744/bapl.202001.003

Espíritu de sus hijas que amontonadas en un rincón de la cama dormían como dos conejos tiernos agazapados uno contra otro, y fue a tocarlas suavemente-. (1974: 176)

En la cita anterior, hay varios aspectos importantes. Uno de ellos es que Espíritu parece, de pronto, volverse un sujeto reflexivo y mostrar algo que solo había demostrado con sus hijas: cierto límite moral. Para ella, las mujeres casadas no son personas a las que ayudaría a tener una relación extramatrimonial. Lo segundo, también bastante complejo, es su declaración de que le hace el «servicio» a Aquilino porque le tiene estima y no por dinero. Antes, ya se había vislumbrado su interés monetario, el cual es sugerido a Aquilino, quien promete no olvidarse de ella (lo cual no será cierto, pues no le ayuda cuando se vuelve «Conde»). Por último, se remarca sus acciones guiadas por su necesidad de alimentar a sus hijas. Ante todo, se destaca su ser maternal, pero este no le es suficiente para salvarse.

Entonces, la ambigüedad de la narradora frente a Espíritu también podría leerse como una forma de reforzar el miedo que se debe sentir hacia ella, pues este sujeto social se convierte en un peligro, ya que no sabemos a qué atenernos con él y cuándo actuará mal o bien. Ante esto, el final de Espíritu debe ser su muerte y así ocupar el menor espacio posible dentro de la nación. Por ello, queda la advertencia de sus hijas. Se debe frenar la situación de esta clase social si es que no se quiere repetir los peligros ya narrados en la historia:

Infeliz mujer- Ayer dejó de existir en el hospital de Santa Ana una infeliz mujer, mulata de raza y de nombre Espíritu Cadenas, que deja en el mayor desamparo dos criaturas del sexo femenino contando una cuatro años escasos y otra seis años aproximadamente. Estos casos de orfandad vienen repitiéndose con dolorosa frecuencia, y sería de desear que la Beneficencia Pública [cursivas añadidas] que dispone de medios más que suficientes crease un asilo de abandonados. (1974: 239-240)

La beneficencia pública, es decir el Estado, debe asumir la educación y el cuidado de estas personas para evitar el peligro que entrañan a una 
nación que quiere concebirse como moderna. La pregunta que queda sería la siguiente: ¿Podrían las hijas educadas (aculturadas) por Espíritu ingresar a la nación imaginada por Matto? No parece haber una respuesta definitiva para ello. Sin embargo, la sociedad peruana actual parece responder que aún quedan muchos problemas socio-raciales-culturales por resolver en el Perú para configurar una verdadera nación.

\section{Conclusión}

En este ensayo he presentado cómo, en la novela Herencia, de Clorinda Matto, Espíritu Cadenas, el personaje afroperuano, es construida a través del sentimiento del miedo, el cual la convierte en un objeto contaminado que es apartado con el fin de no dañar el futuro de la nación. En ese sentido, he expuesto cómo esta novela está influenciada por el naturalismo, aunque con ciertos límites propios de la situación problemática que las mujeres escritoras finiseculares tienen con este género. Es claro que, en esta obra de Matto, se observa en la herencia femenina, la cual determina las relaciones de salvación o perdición. Asimismo, se reactualiza y evidencia cómo circula en el imaginario decimonónico, y por qué no hasta ahora, una narrativa del miedo hacia el sujeto afroperuano, el cual es alimentado por una serie de estereotipos que, para el caso de esta novela, lo vinculan con lo erótico y sexual.

En relación a Espíritu Cadenas, se destacó su configuración corporal, sexual y viciosa, la cual termina por justificar su deceso y representa la necesidad de que este tipo de sujetos sociales ocupen simbólicamente cada vez menos espacio en la nación. Ella cumplió un papel celestinesco entre Aquilino Merlo y Camila Aguilera, el cual se materializa de diversos modos. Uno de ellos es que Espíritu impulsa el deseo de Aquilino por Camila y posibilita que este tenga éxito. Funda, además, una alianza estratégica con el inmigrante italiano que terminará precipitando la decadencia física y moral de Camila, lo que imposibilita que se convierta en un futuro ángel del hogar. Al final de la novela, su fácil acceso al espacio privado termina siendo denunciado como el modo en que este sujeto social precipita la deshonra de las familias peruanas. 
https://doi.org/10.46744/bapl.202001.003

Entonces, el sujeto afroperuano, desde Herencia, ha sido construido para ser temido. No es posible que, en la representación que se hace de Espíritu Cadenas dentro de la novela (es decir, sin una educación occidental), esta clase social sea simbólicamente salvada, sino que su muerte se convierte en necesaria. Esto no sucede con Margarita Marín, mestiza aculturada, que se vuelve, por su herencia serrana y su educación occidental, en la fundadora de la nación peruana moderna imaginada por Matto. 
https://doi.org/10.46744/bapl.202001.003

\section{BIBLIOGRAFÍA}

AHMED, S. (2004). The affective politics of fear. The cultural politics of emotion, pp. 62-81. New York: Routedge.

BASADRE, J. (2005) [1968]. Historia de la República del Perú (1822-1933). Lima: El Comercio.

BOLUFER, M. (1998). Mujeres e ilustración. La construcción de la feminidad en la ilustración española. Valencia: Instituto Alfons El Magnanim y Diputació de valéncia.

DENEGRI, F. (2003). Distopía poscolonial y racismo en la narrativa del XIX peruano. En Scarlett O'phelan y Margarita Zegarra (eds). Familia y vida cotidiana en América Latina. Siglo XVIII-XX, pp. 117-135. Lima: Pontificia Universidad Católica del Perú.

KLAIBER, J. (1978). Los "cholos" y los "rotos": actitudes raciales durante la Guerra del Pacífico. Histórica, II (1), 27-37.

MANNARELLI, M. (1999). Sexualidad y cuerpo femenino. Nuevos discursos y transformaciones sociales en Lima a fines del siglo XIX y principios del XX. En Zegarra, Margarita (ed.). Mujeres y género en la historia del Perú, pp. 347-363. Lima: CENDOC-MUJER.

MALLQUI, F. (2013). En busca de la nación moderna: la representación fantasmática de la modernidad en "Herencia" de Clorinda Matto de Turner (1895). Tesis de Maestría en Literatura. Lima: Pontificia Universidad Católica de Lima, Escuela de Postgrado.

MATTO, C. (1974) [1895]. Herencia. Lima: Instituto Nacional de Cultura.

MAYNA, M. (2010). La figura de la beata en El padre Horán (1848): la nación, el discurso moderno y la mujer. Boletín del Instituto Riva Agüero, (35), 89-101. 
https://doi.org/10.46744/bapl.202001.003

NASH, M. (s/f ). Identidades de género, mecanismo de subalternidad y procesos de emancipación femenina. CIDOB $D^{\prime}$ Afers internacionals, (73-74), 39-57.

NUSSBAUM, M. (2014). Los enemigos de la compasión: el miedo, la envidia, la vergüenza. Emociones políticas. ¿Por qué el amor es importante para la justicia?, pp. 379-455. Barcelona: Paidós.

OLIART, P. (1995). Poniendo a cada quien en su lugar: estereotipos raciales y sexuales en la Lima del siglo XIX. En Aldo Panfichi y Felipe Portocarrero (eds). Mundos interiores: Lima 1850-1950, pp. 261-288. Lima: Universidad del Pacífico.

PELUFFO, A. (2005). De Killac a Lima: Modelos y anti-modelos de virtud republicana en Herencia. En Lágrimas andinas: Sentimentalismo, género y virtud republicana en Clorinda Matto de Turner, pp. 203-246. Pittsburgh: Instituto Internacional de Literatura Iberoamericana / Universidad de Pittsburgh.

VELÁZQUEZ, M. (2003). Las mujeres son menos negras: el caso de las mujeres esclavas en la Lima del siglo XIX. En Narda Enriquez, Narda (ed.). El hechizo de las imágenes. Estatus social, género y etnicidad en la historia peruana, pp. 57-97. Lima: Pontificia Universidad Católica del Perú, Fondo Editorial. 